\title{
Preface: Selected papers from the 30th SEGH Conference on Environmental Geochemistry and Health
}

\author{
Jane Entwistle $\cdot$ Andrew Hursthouse
}

(C) Springer Science+Business Media Dordrecht 2015

This special issue brings together invited contributions from the 30th International SEGH Conference (European Section) which was hosted by Northumbria University, in Newcastle upon Tyne, UK from the 30 June-4 July 2014. The meeting saw 120 participants from over 25 countries presenting the results of research and strategic reviews and provided a platform for interaction between international scientists, consultants, regulatory authorities and other public health practitioners engaged in the multidisciplinary areas of environment and health. Keynote lectures, oral presentations and posters crossed the range of SEGH issues from essential trace elements and health (iodine) through exposure assessment in air quality and soil, to topical issues of hydraulic fracturing and risk, bioavailability and bioaccessibility.

With increasing public awareness of the links between health and the environment, and increasing pressures on resources and resource management, the conference aimed to stimulate debate and innovation in responding to demands for advances in the science,

J. Entwistle $(\bowtie)$

Department of Geography, Northumbria University,

Newcastle upon Tyne, UK

e-mail: Jane.Entwistle@northumbria.ac.uk

\section{A. Hursthouse}

School of Science and Sport, University of the West of Scotland, Paisley, UK

e-mail: Andrew.Hursthouse@uws.ac.uk practice and policy of health focussed environmental geochemistry. In this special issue we have been fortunate enough to collect high quality representative articles from across the range of topics that made such a successful meeting possible.

The importance of iodine in public and fetal health, the iodine 'state-of-the-(EU)nation' and our current knowledge of health implications of mild-moderatesevere iodine deficiency are authoritatively reviewed at the start of this issue. Air pollution and contaminated land as key public health issues, and the assessment of environmental exposure to dusts from a variety of urban sources are detailed in selected case studies, with contributions covering a range of potentially harmful elements (PHEs).

Central SEGH themes of risk assessment, bioavailability and bioaccessibility are further explored with a focus on understanding how the chemical properties of water, soil, plant uptake dynamics and food preparation influence the movement of PHEs from the environment into our bodies.

On behalf of the Society for Environmental Geochemistry and Health, we would like to thank all the participants of SEGH 2014 for their involvement, the authors for their contributions, and the reviewers for their timely and constructive feedback during the collation of this special issue. Thank you also to the Editor-in-Chief of EGaH, Prof. Ming H. Wong, and the production staff in Springer. 